\title{
THE PROFESSIONAL WOMAN AS MOTHER
}

\author{
Lois Wladis Hoffman \\ The University of Michigan \\ Ann Arbor, Michigan 48104
}

In talking about the professional woman as mother, one could deal with the effects of the career on her mothering, the effects of motherhood on her career, or the effects of combining these two roles on her personal satisfactions. Most of my focus will be on the first: what kind of a mother is she, and ho'w have her children turned out? But let me discuss the other two briefly, for they provide an important context for my major points.

The dysfunctions of motherhood for the pursuit of a career have been pointed out by Bailyn, ${ }^{1}$ Epstein, ${ }^{2}$ White, ${ }^{3}$ and others. We are handicapped in our carèer advancement by geographical restrictions, family obligations, guilt, and prejudice. The husband's career considerations have been given priorities not only because of his insistence, but also because of our acquiescence. We have been assigned, and we have accepted, the major responsibility for child care and the household operations. As Rossi ${ }^{4}$ has indicated, some men also have not pursued their careers with single-minded devotion, but have allowed their family concerns to temper their ambitions. But this is far more true for women. Furthermore, women have had that mixed blessing-the chance to drop out without censure. We have all returned from a bad day at work to a chaotic household and wondered why we ever left the kitchen. We are harassed, overworked, and in desperate need of a housekeeper.

But for all of this, we may have fared better with respect to personal satisfactions than had we chosen one of the alternative paths that were available. This is not to say that there is no room for improvement, but the life that includes a commitment to the several roles-wife, mother, and professional-may be the richest of all. There are a number of recent empirical studies indicating that despite all of the difficulties, the bright and educated women who have combined all three look back with considerable satisfaction and a minimum of regrets. ${ }^{5-8}$ Birnbaum, ${ }^{8}$ for example, compared a group of mothers who were also faculty members of a large university with unmarried faculty women, and with a group of mothers who had graduated from college with honors but who had pursued neither further education nor a career. The groups were comparable with respect to age-mainly in their early forties. Of the three groups, the nonworking mothers were the ones with the lowest self-esteem and the lowest sense of personal competence, including even sense of competence about child-care skills. These women also felt least attractive, expressed most concern over self-identity issues, and most often indicated feelings of loneliness. The subjects were asked what they felt was missing from their lives and the predominant answer from the two groups of professional women was time, but for the housewives it was challenge and creative involvement. The single women, in this study as in others, ${ }^{9}$ held higher professorial ranks than the married professionals. Both professional groups indicated high self-esteem and a sense of competence, but the single women were lonelier and somewhat less comfortable in their social relationships.

The data indicate then that the woman who has combined a career with marriage and children has not pursued her career with the total undeviating involvement that has characterized men and single women. She has, in many cases, withdrawn from full career commitments when her children were young, returning 
to these commitments as they matured..$^{5,10,11}$ Her life has had more variety; growing old has not meant simply a dimnution of her powers, but instead she has experienced greater flexibility in responding to the various possibilities that life offers at different stages in the life cycle. This may seem a waste from the standpoint of a society oriented exclusively to productivity in work, but to many it seems a more fulfilling life. I am not even sure that it is a waste in terms of the criterion of productivity, for the woman with the combined roles may retain an enthusiasm and creativity in her work even in her very mature years, when many men who have constantly pursued their careers become bored, stagnant, and bureaucratized.

In turning now to the major focus of this presentation-the effects of the mother's professional role on the child-there is a remarkable lack of data. In part, this is a methodological problem. Studies that have examined the effects of maternal employment on the child usually locate a group of children around the same age, half of whom have employed mothers and half of whom do not, and compare the two groups. Since more than half the mothers whose youngest child is in school are employed, finding these groups is no great problem. But to find a group of children of the same age whose mothers have professions is obviously more difficult. In fact, I know of few such studies. We shall have to rely on those that have compared employed and unemployed mothers' children among the highly educated, or middle class. This can be supplemented with studies that have questioned professional mothers but have not obtained direct data on the children.

Ten years ago I published with Ivan Nye a book on the working mother, ${ }^{12}$ The working mother had been considered quite a devil, and a great deal of the research reported in the book had originally been undertaken in the hope of documenting the ill effects of maternal employment. But the data simply would not cooperate. Examined as a general phenomenon, the standard study with adequate controls yielded no significant differences between the children of working and nonworking women. That should not have been a surprise. Maternal employment is too heterogeneous a variable to study. To see the effects, we have to break it down, for the effects will be different in the working class than in the middle class. They will be different if the mother works out of necessity than if she works out of choice. The effects will be different for young children than for older, for girls than for boys. The hours she works, her child-care and household arrangements, her attitudes about her role, all will be important. But even those studies which introduced such breakdowns found few negative effects and several positive ones. There was one study, however, that suggested a bit of caution.

This was a study that I did of working mothers of elementary school age children. The working mothers were divided into those who liked their work and those who did not. Each was compared with a nonworking mother family that was matched with respect to social class, size of family, and other pertinent factors. As you can guess, the women who liked their work were more typicallythough not exclusively-the middle class, and better educated. The results indicated that when the working mother liked her work she often seemed to feel guilty, and she compensated for her employment to such an extent that she may have even gone too far. For example, her children helped less around the house than did the children of the nonworking mothers. There was much in her relationship with her children that was very positive-she expressed more positive affect, used less coercive discipline, she felt less hostility toward her children and more empathy-but in many cases she was somewhat overindulgent, and the children reflected this in their peer interactions and school performance. They played 
more with younger children than with their age mates; they were less likely to initiate interaction with their classmates; their academic performance was not up to par. These are almost the only negative effects of maternal employment found in the middle class to date, and they appear to result not from employment per se but from guilt about employment. This pattern was not extreme, and it was not found in a study of working mothers with adolescent children. It is important, however, because it indicates it may not be employment one has to worry about, but guilt about employment.

With the exception of the finding just mentioned, there is little evidence that maternal employment has a negative effect, and considerable support for the idea that it has a positive effect, particularly on girls. The daughters of working mothers are more likely to choose their mothers as models and as the person they most admire. Adolescent daughters of working mothers, particularly in the middle and upper socioeconomic groups, have been found to be active, autonomous, girls who admire their mothers but who are not unusually close-tied to them. For girls of all ages, having a working mother contributes to a concept of the female role that includes less restriction and a wider range of activities, and a self-concept that incorporates these aspects of the female role. They usually approve of maternal employment, plan to work when they grow up and become mothers, and, if they are old enough, they are more often employed themselves. ${ }^{12}$

A few years ago a study by Goldberg ${ }^{13}$ indicated that undergraduate women tended to undervalue journal articles when authorship was attributed to women. Recently, Grace Baruch ${ }^{14}$ replicated this study. She found that the tendency to undervalue the works attributed to women was less than in the earlier study, and that the daughters of working mothers showed no such tendency. That is, the daughters of working mothers, unlike those of nonworking mothers, did not assume that women were less competent than men. In this study, the college women who wanted to combine motherhood with a career most often came from homes in which the mothers had successfully combined the two roles. But simply having a mother who was employed was enough to affect the daughter's judgment about the competence of women, and this, of course, implies a positive effect on her self-concept.

If we focus on the daughter's academic and career achievements, we find further evidence of the positive effects of having a professional mother. A number of investigations ${ }^{8,15,16,28}$ have found that highly achieving women and women who aspire to careers, particularly to less conventionally feminine careers, are more likely to be the daughters of educated women and the daughters of employed women.* The high-achieving woman has a high-achieving daughter. There are several reasons why this may be the case. Various studies suggest that the optimum conditions for a high-achieving female include the presence of a model, and the model of the professional woman is more relevant to academic and achievement goals than is that of the nonemployed housewife. The optimum conditions for achievement also include independence training, which is particularly important because many girls are handicapped by overprotection and encouragement of dependency. And finally, optimum conditions include a good relationship with a father who encourages the girl's independence and achievement while accepting her as a female.$^{5,17}$ All of these conditions are more likely to exist in the family with a professional mother.

\footnotetext{
- Birnbaum's ${ }^{8}$ married professional women are themselves the daughters of educated, employed women. However, the pattern for single professionals is somewhat different, as indicated in both Birnbaum's data and Astin's.10
} 
Nor is this simply conjecture. We have already discussed the professional mother as model. Regarding the encouragement of independence, the study by Birnbaum ${ }^{8}$ mentioned earlier compared the two groups of mothers, professional women and intelligent nonworking housewives, with respect to their attitudes about their children. The professional mothers indicated pleasure in the child's growing independence. For the nonworking mothers, on the other hand, the child's movement toward independence was disturbing, perhaps because their own importance diminished as the child needed them less. Overprotection by the nonworking mothers was also suggested by the fact that they seemed to worry excessively about their children's health and safety, and they stressed self-sacrifice as a major aspect of motherhood.

With respect to the last-named factor that contributes to the development of achievement orientations in women-having a close relationship with an encouraging and supportive father-there are data also. Many studies have found that the husbands of working women are more actively involved in the care of the children, and other studies show that the active involvement of the father has a positive effect on both male and female children. Furthermore, the data indicate that the husbands of professional women are more likely to respect competence and achievement in women. ${ }^{7,12,18-20}$

There is very little else by way of solid data that differentiates the children of professional from nonprofessional mothers. For example, I have not discussed the effects on sons simply because we have not yet learned what these effects may be. $\dagger$

There are, however, some hints about possible effects from the studies that have compared professional mothers with able women who are full-time housewives. Several studies, for example, have indicated that the woman who does well in college but does not pursue a career pins her achievement needs on to her children seeking vicarious satisfaction through their achievements. ${ }^{\mathbf{8 1 5}}$ Although her achievement frustrations are not great when her children are young, they tend to increase after a few years. ${ }^{21}$ Several studies indicate that about twelve or more years after marriage $\ddagger$ her need for achievement rises; her self-esteem is low; her feeiing of self-sacrifice is high; she is prone to depression; she worries about her competence in general and particularly as a mother; she is very anxious about her children and guilty about occasional losses of her self-control., $8,22,23$ Despite her eagerness for her children to achieve, she is, as already pointed out, ambivalent about their growing independence. Surely this situation-the plight of the bright, nonprofessional mother when her children have reached school agedoes not seem conducive to rearing healthy, competent children of either sex. When the professional mother is feeling harassed and guilty about her employment, she might consider the alternative.

We do not have data on the effects on the child of the various career patterns that professional women have chosen. How important, for example, is the fact that so many professional women have reduced their work load when the children were young? Is the prevalence of this pattern one of the reasons why maternal employment has not been found to have adverse effects? What, indeed, is the

$\dagger$ There are a few limited studies. For example, in a study of a small sample of gifted boys, the low achievers had more employed mothers, but the high achievers had more professionally employed mothers, and another study which did not separate boys from girls found the children of professional women had better reading skills than a matched sample of full-time housewives. ${ }^{30}$

$\ddagger$ More specifically, about fifteen years after college graduation. 
effect of the mother's career pursuits on the very young child? We simply do not know. Those who oppose professions for mothers are quick to generalize from the studies of maternal deprivation showing that infants reared in inadequate institutions without any stable one-to-one relationship with an adult suffer serious affective and cognitive deficits. These early and important studies, however, do not provide automatic condemnation of day-care centers, various alternative foster-care arrangements, or even of institutional care itself if the institution is appropriately set up. Research suggests, for example, that putting a small number of babies in the attentive care of a single person mitigates many of the adverse effects. So does increasing the stimulation potential of the physical environment. In any case, the connection between the sterile, understaffed, institutional environment and the setting provided by the professional mother seems remote to me.

On the other hand, we do not know what the effects of the mother's career are on the very young child or what the effects are of the various possible child care arrangements. No one has studied them.

And now, if you feel that I have painted a bleak picture of the state of our knowledge about the effects of the mother's career on her child, let me add still further to that impression; for much that we know may be made obsolete by the recent changes in sex-role prescriptions.

The existing research, such as it is, is for the most part based on women who have been married about fifteen years or more. We had our babies during the time well characterized by the term The Feminine Mystique. From the midforties until recently, large families were desired and motherhood was extolled as woman's major role whether she was a professional or not. Freudian theory, or at least the emphasis on the crucial importance of the mother in molding the personality of her child, was at its peak, and the Bowlby and Spitz views on maternal deprivation added a shocking imperative to the mother's presence. This may have made those of us who pursued careers feel guilty, but it may have also alerted us to compensatory responses that had a very positive effect on our children's development. Thus, if the data show, and I think that on the whole they do, that we have done quite well as mothers, maybe it is because we tried extra hard.

On the other hand, we were harassed! Not content with being professionals and mothers, we wanted to be gourmet cooks, hostesses, supportive wives, and femme fatales. The major problem reported by the professional woman in several studies has been the management of the household. The difficulty of finding a housekeeper really was the single most predominant complaint of the women Ph.D.'s studied by Astin. ${ }^{10}$ And our husbands may have helped more than the husbands of the nonworking women, but by no means was there equal responsibility for housework and child care. . $^{6.7}$

Much in this situation, however, has changed in recent years, and it is only with great caution that we can generalize from the existing data to the case for the new career women. For one thing, there will be more of them. Data collected each year on incoming freshmen at several colleges and universities show a continual increase in the percentage of women planning to combine careers and motherhood. ${ }^{24,25}$ These younger women who will pursue careers may be quite different in values, self-concepts, and expectations.

If they marry, they will very likely marry a different kind of man than any we might have married, one for whom achievement and career lines are much less central. When Horner ${ }^{26}$ did her research in 1965 on the motive to avoid success, this motive characterized women, but not men. In an exact replication, at the same school, we found just six years later that men were as likely as 
women to show evidence of a motive to avoid success. The percentage of men showing this motive had increased from $8 \%$ in 1965 to $78 \%$ in 1971 . The dynamics of this motive in men is probably very different from what it is in women, but the finding does reflect a real change in men's orientations toward academic and career goals. We older women of ten gave our husbands' careers precedence over ours, in part because we felt it was a more intrinsic part of his self-concept. College men today are very different in this respect. This may augur well for the young woman who wishes to combine the mother and professional roles. The true sharing of household tasks, child care, and career commitment by man and wife may well be a viable possibility, whereas this has been only rarely the case until now. ${ }^{6,7,20}$ Furthermore, if these women do become mothers, the styles of mothering may also have changed. Child-care centers may be more available and more acceptable. The pattern of women interrupting their careers for the early child-rearing years may diminish.

Finally, not marrying and not having children may be more psychologically available options than they used to be. In a recent study at the University of Michigan we found that ten percent of the undergraduate women said they wanted no children $\S$ and the same percentage was found by Lozoff ${ }^{27}$ at Stanford. This is not a high percentage, but it is considerably higher than previous comparable figures.

These changes must be kept in mind when we consider the data on the professional woman as mother. Very likely it will be easier to combine the two roles, for there will be more social acceptance and institutional supports for doing so. Earlier I indicated that balancing a career commitment with family and affective concerns has resulted for many of us in a richer and more fulfilling life. I think the possibility of achieving such a balance will be greater for the young professional woman of the near future, and for her husband as well. Needless to say, the lives of many men would also be enriched if they too had combined roles.

$\S$ These figures are higher if we include those who said they wanted only adopted children.

\section{References}

1. BaILYN, L. 1964. Notes on the role of choice in the psychology of professional women. Daedalus. Spring : 700-710.

2. Epstein, C. F. 1970. Woman's Place: Options and Limits in Professional Careers. University of California Press. Berkeley, Calif.

3. WhITE, M. S. 1970 . Psychological and social barriers to women in science. Science 170.

4. Rossi, A. 1971. Assessing women's history: our feminist predecessors. Presented at Center for Continuing Education of Women. University of Michigan. Ann Arbor, Mich. Oct. 19.

5. Ginzzerg, E. 1971. Educated American Women: Life Styles and Self-Portraits. Paperback. Columbia University Press. New York, N. Y.

6. Poloms, M. M. 1972. Role conflict and the married professional woman. In Toward a Sociology of Women. Constantina Safilios-Rothschild, Ed. Xerox College Publishing. Lexington, Mass.

7. GarLand, T. N. 1972. The better half? The male in the dual profession family. In Toward a Sociology of Women. Constantina Safitios-Rothschild, Ed. Xerox College Publishing. Lexington, Mass.

8. Birnanum, J. A. 1971. Life patterns, personality style and self esteem in gifted family oriented and career committed women. Unpublished doctoral dissertation. University of Michigan. Ann Arbor, Mich.

9. Simon, R. J., S. M. Clark \& K. Galway. 1970. The woman Ph.D.: A recent profile. In The Impact of Fertility Limiation on Women's Life Career and Personality. E. Milner, Ed. Ann. N. Y. Acad. Sci. 175(3) :.

10. Astin, H. S. 1969. The Woman Doctorate in America. The Russell Sage Foundation. New York, N. Y. 


\section{Hoffman: The Professional Woman as Mother}

11. Feldman, S. D. 1971. Girls stay away from the boys: marital status and graduate education. Presented at Pacific Sociological Assoc. Mtgs. Honolulu, Hawaii.

12. Nye, F. \& L. W. Hoffman. 1963. The Employed Mother in America. Rand McNally. Chicago, Ill.

13. Goldberg, P. 1967. Misogyny and the college girl. Presented at the meeting of the Eastern Psychological Assoc. Boston, Mass. April.

14. BARUCH, G. K. 1972. Maternal influences upon college women's attitudes toward women and work. Developmental Psychol. 6(1): 32-37.

15. TANGRI, S. S. 1969. Role innovation in occupational choice. Doctoral dissertation. University of Michigan. Ann Arbor, Mich.

16. ALMquIST, E. M. \& S. S. ANGRIST. 1971. Role model influences on college women's career aspirations. Merrill-Palmer Quarterly 17(3): 263-279.

17. HofFMAN, L. W. 1972. Early childhood experiences and women's achievement motives. J. Social Issues 28(2): 129-155.

18. Dizard, J. 1968. Social Change in the Family. Community and Family Study Center. University of Chicago. Chicago, Ill.

19. MАсCOBY, E. E. 1966. Sex differences in intellectual functioning. In The Development of Sex Differences. E. E. Maccoby, Ed. Stanford University Press. Stanford, Calif.

20. RAPOPORT, R. \& R. RAPOPORT. 1972. The dual-career family: A variant pattern and social change. In Toward a Sociology of Women. Constantina Safilios-Rothschild, Ed. Xerox College Publishing. Lexington, Mass.

21. Veroff, J. \& S. Feld. 1970. Marriage and Work in America. Van Nostrand Reinhold Co. New York, N. Y.

22. BaRUCH, R. 1967. The achievement motive in women: Implications for career development. J. Personality and Social Psychol. 5(3): 260-267.

23. Chessler, P. 1972. Women and mental illness. Presented at Conf. on Women: Resource for a changing world. Sponsored by Radcliffe Institute, Radcliffe College. Cambridge, Mass. April $17 \& 18$.

24. Cross, K. P. 1971. Beyond the Open Door. Jassey-Bass, Inc. San Francisco, Calif.

25. UNIVERSITY RECORD. 1972. ACE on "typical" freshman - M. Frosh: still ambitious but success not utmost. University of Michigan. Ann Arbor, Mich. Apr. 3: 3.

26. HORNER, M. S. 1968. Sex differences in achievement motivation and performance in competitive and non-competitive situations. Doctoral dissertation. University of Michigan. Ann Arbor, Mich. University Microfilms.

27. Lozoff, M. M. 1972. Changing life styles and role perceptions of men and women students. Presented at Conf. on Women: Resource for a changing world. Sponsored by Radcliffe Institute, Radcliffe College. Cambridge, Mass. April 17 \& 18.

28. LEVINE, A. G. 1968. Marital and occupational plans of women in professional schools: law, medicine, nursing, teaching. Unpublished doctoral dissertation. Yale University. New Haven, Conn.

29. FranKel, E. 1964. Characteristics of working and non-working mothers among intellectually gifted high and low achievers. Personnel and Guidance J. Apr. : 776-780.

30. Jones, J. B., S. W. Lundsteen \& W. B. Michael. 1967. The relationship of the professional employment status of mothers to reading achievement of 6th grade children. California J. Educ. Research 43(2): 102-108. 